
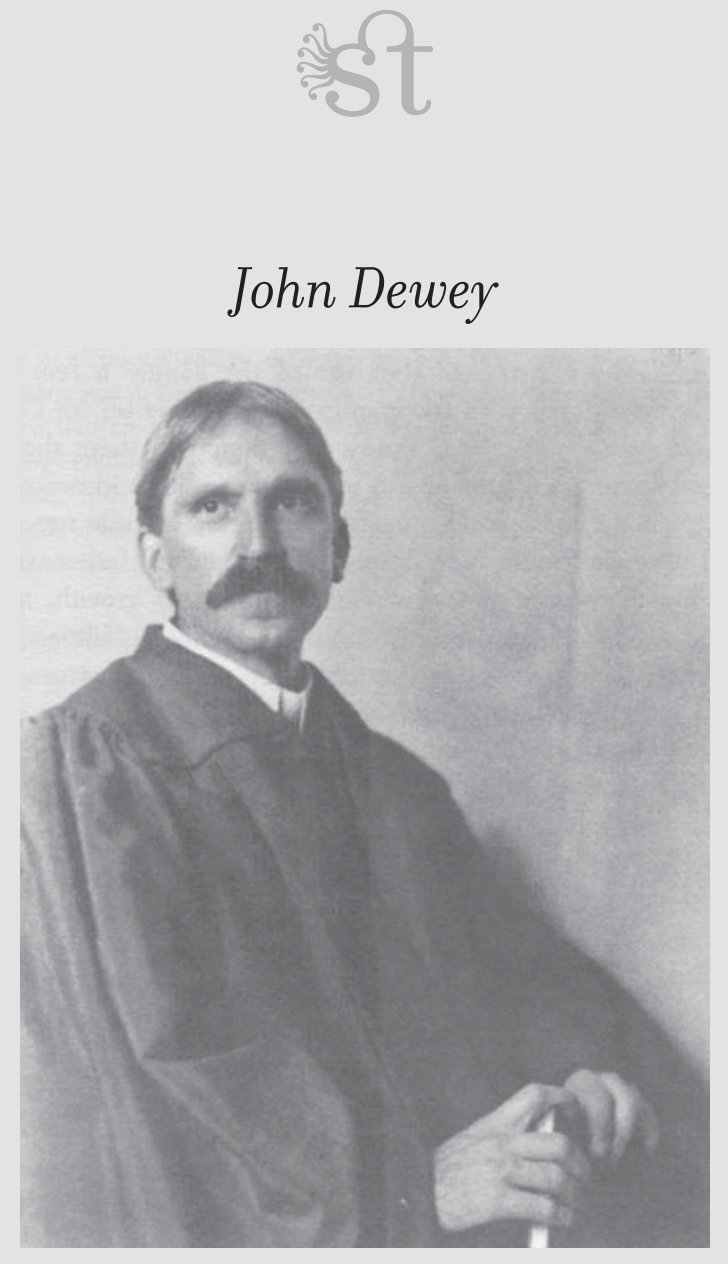

\title{
O desenvolvimento do pragmatismo americano ${ }^{1}$
}

O propósito deste artigo é definir as principais teorias dos movimentos filosóficos conhecidos com os nomes de pragmatismo, instrumentalismo ou experimentalismo. Para tanto, devemos traçar seus desenvolvimentos históricos; pois esse método parece apresentar-se como a maneira mais simples de compreender tais movimentos e, ao mesmo tempo, evitar certos mal-entendidos correntes a respeito de suas doutrinas e de seus objetivos.

A origem do pragmatismo remonta a Charles Sanders Peirce, que era filho de um dos mais celebrados matemáticos dos Estados Unidos, ${ }^{2}$ sendo ele próprio muito proficiente na ciência matemática. Foi um dos fundadores da moderna lógica simbólica das relações. Infelizmente, Peirce não era em absoluto um autor sistemático e nunca expôs suas idéias por meio de um sistema único. O método pragmático por ele desenvolvido 
aplica-se somente a um universo de discurso estreito e limitado. Após William James ter estendido o escopo do método, Peirce escreveu uma exposição sobre a origem do pragmatismo tal como ele primeiramente o havia concebido; é dessa exposição que retiramos as passagens a seguir.

O termo "pragmático", contrariamente àqueles que consideram o pragmatismo como uma concepção exclusivamente americana, foi sugerido a Peirce em razão de seu estudo de Kant. Em A metafísica da moral, Kant estabeleceu uma distinção entre pragmática e prática. A última aplica-se a leis morais que Kant considera como sendo a priori, enquanto a primeira aplica-se às regras da arte e da técnica que estão baseadas na experiência e são aplicáveis à experiência. Peirce, que era um empirista, com hábitos mentais, tal como ele dizia, de laboratório, recusava chamar seu sistema de "praticalismo", como sugeriram alguns de seus amigos. Na qualidade de lógico, estava interessado na arte e técnica do pensar real e, no que concerne ao método pragmático, especialmente interessado na arte de clarificar conceitos ou de construir definições adequadas e efetivas de acordo com o espírito do método científico.

Nas palavras do próprio Peirce, para uma "pessoa que ainda pensava mais prontamente em termos kantianos, 'praktish' e 'pragmatisch' eram tão distantes quanto dois pólos; o primeiro pertencendo a uma região do pensamento, na qual nenhuma mente de tipo experimental pode encontrar terreno sólido sob seus pés, e o último expressando a relação a algum propósito humano definido. Ora, de fato, o aspecto mais premente da nova teoria era o reconhecimento de uma conexão indissolúvel entre cognição racional e propósito racional."*

Ao aludir ao tipo de mente experimental, somos levados ao significado exato fornecido por Peirce para a palavra "pragmático". Ao descrever um experimentalista como sendo um homem cuja inteligência é formada no laboratório, ele afirma: "Qualquer asserção que se possa fazer ao experimentalista, ele a entenderá como significando que se uma dada prescrição para um experimento for alguma vez fornecida e efetivamente realizada, resultará em uma experiência de uma dada descrição, ou ainda, não verá sentido algum no que foi dito". E, portanto, Peirce desenvolveu a teoria de que "o propósito racional de uma palavra ou de outra expressão repousa exclusivamente em relações concebíveis com a conduta de vida; de modo que, como obviamente nada que não possa resultar de um experimento pode ter alguma relação direta com a conduta, se alguém consegue definir acuradamente todos os fenômenos experimentais concebíveis que a afirmação ou negação de um conceito poderia implicar, esse alguém terá assim uma definição completa do conceito".*

* Monist, vol. 15, p. 163.

** Ibid., p. 162. 
O ensaio no qual Peirce desenvolveu sua teoria possui o título: Como tornar nossas idéias claras. * Aqui há uma notável similaridade com a doutrina kantiana. O esforço de Peirce era o de interpretar a universalidade dos conceitos no domínio da experiência, da mesma maneira que Kant estabeleceu a lei da razão prática no domínio do a priori. "O significado racional de toda proposição repousa no futuro... Mas das inúmeras formas nas quais uma proposição pode ser traduzida, qual delas pode ser chamada de seu próprio significado? De acordo com o pragmatista, é aquela forma em que a proposição torna-se aplicável à conduta humana, não nessas ou naquelas circunstâncias especiais, tampouco quando alguém pensa nesse ou naquele padrão especial, mas sim aquela que é mais diretamente aplicável ao autocontrole sob todas as circunstâncias e para todos os propósitos".* Assim também, "o pragmatista não faz o summum bonum consistir em ação, mas faz com que consista naquele processo de evolução pelo qual o existente vem cada vez mais incorporar o geral...", *** em outras palavras - o processo pelo qual o existente, com a ajuda da ação, torna-se um corpo de tendências racionais ou de hábitos generalizados tanto quanto possível. Essas declarações de Peirce são praticamente conclusivas com respeito a dois erros que são usualmente cometidos no que concerne às idéias do fundador do pragmatismo. Usualmente se diz que o pragmatismo faz da ação a finalidade da vida. Também se diz que o pragmatismo subordina o pensamento e a atividade racional a fins de interesse e ganho particulares. É verdade que a teoria, de acordo com a concepção de Peirce, implica essencialmente em uma certa relação com a ação, com a conduta humana. Mas o papel da ação é aquele de um intermediário. Para estar apto a atribuir significado aos conceitos deve-se poder aplicálos à existência. Ora, é por meio da ação que essa aplicação se torna possível. E a modificação da existência que resulta dessa aplicação constitui o verdadeiro significado dos conceitos. O pragmatismo está, por conseguinte, muito distante daquela glorificação da ação pela ação, que é considerada como a característica peculiar da vida americana.

Outra coisa a ser notada é que há uma escala de aplicações possíveis dos conceitos à existência e, por conseguinte, uma diversidade de significados. Quanto maior a extensão dos conceitos, quanto mais eles se encontram livres de restrições que os limitem a casos particulares, tanto mais se torna possível para nós atribuir a maior generalidade de significado ao termo. Assim, a teoria de Peirce se opõe a toda restrição do significado de um conceito em razão de resultados de um fim particular, ainda mais quando se trata de um objetivo pessoal. Opõe-se ainda mais fortemente à idéia de que a razão ou o pensamento devessem ser reduzidos a meros servos de qualquer interesse

* Popular Science Monthly, 1878 .

** Monist, vol. 15 , p. $17^{3-1} 74$.

**** Ibid., p. $17^{8}$. 
estreito ou pecuniário. Em sua origem, o pragmatismo é americano na medida em que insiste sobre a necessidade da conduta humana e sobre a satisfação de algum objetivo para clarificar o pensamento. Mas, ao mesmo tempo, o pragmatismo desaprova aqueles aspectos da vida americana que fazem da ação um fim em si mesmo e que concebem os fins de maneira estreita e muito "praticamente". Ao considerar um sistema filosófico em suas relações com fatores nacionais, é necessário manter em mente não somente aqueles aspectos da vida que estão incorporados no sistema, mas também os aspectos contra os quais o sistema protesta. Nunca houve um filósofo que tenha merecido tal título simplesmente pela razão de haver glorificado as tendências e características de seu ambiente social; assim como nunca houve um filósofo que não tenha sido influenciado por certos aspectos da vida de seu tempo, idealizando-os.

O trabalho começado por Peirce foi continuado por William James. Em certo sentido, James estreitou a aplicação do método pragmático de Peirce, mas ao mesmo tempo ele o estendeu. Os artigos escritos por Peirce em 1878 quase não despertaram atenção nos círculos filosóficos, na época sob a influência dominante do idealismo neokantiano de Green, de Caird e da escola de Oxford, excetuando aqueles círculos onde a filosofia escocesa do senso comum manteve sua supremacia. Em 1898, James inaugurou o novo movimento pragmático em uma palestra intitulada "Concepções filosóficas e resultados práticos" mais tarde impressa no volume Collected essays and reviews (Ensaios e resenhas coligidos). Mesmo nesse estudo inicial, pode-se facilmente notar a presença daquelas duas tendências de restringir e, ao mesmo tempo, estender o pragmatismo anterior. Depois de citar a consideração psicológica formulada por Peirce, segundo a qual "as crenças são realmente regras de ação e toda a função do pensar não é nada mais do que um passo na produção dos hábitos de ação", e que toda idéia que formamos de um objeto para nós mesmos é realmente uma idéia dos possíveis efeitos daquele objeto, James expressou a opinião de que todos esses princípios poderiam ser expressos mais amplamente do que foi feito por Peirce. "Para nós, o teste final do que significa uma verdade encontra-se realmente na conduta que isso dita ou inspira. Mas tal conduta é inspirada porque prevê alguma mudança particular de nossa experiência que clamará exatamente por aquela conduta de nossa parte. E eu preferiria expressar o princípio de Peirce afirmando que o significado efetivo de qualquer proposição filosófica pode sempre ser colocado em termos de alguma conseqüência particular em nossa experiência prática futura, seja ativa ou passiva; o que se assenta mais sobre o fato de que essa experiência deve ser particular, do que sobre o fato de que deve ser ativa". Em um ensaio escrito em 1908, James repete a afirmação e assinala que toda vez que emprega o termo "o prático," ele com isso quer dizer "o distintamente concreto, o

\footnotetext{
* Collected essays and reviews, p. 142.
} 
individual, o particular e efetivo, em oposição ao abstrato, geral e inerte - 'pragmata' são as coisas em sua pluralidade - conseqüências particulares podem perfeitamente ser de natureza teorética."*

William James alude ao desenvolvimento que ele mesmo deu à expressão peirceana do princípio [pragmático]. Em certo sentido, pode-se dizer que ele estendeu o escopo do princípio ao substituir, pelas conseqüências particulares, a regra ou método geral aplicável à experiência futura. Mas, em outro sentido, essa substituição limitou a aplicação do princípio, pois destruiu a importância atribuída por Peirce à maior possibilidade de aplicação da regra ou do hábito de conduta - sua extensão à universalidade. É o mesmo que dizer que William James era muito mais nominalista do que Peirce.

Pode-se notar uma ampliação do pragmatismo na passagem acima. Nela, James alude ao uso de um método na determinação do significado da verdade. Dado que a verdade é um termo e conseqüentemente tem um significado, essa ampliação é uma aplicação legítima do método pragmático. Mas cabe notar que aqui esse método serve apenas para aclarar o significado do termo "verdade", e isso nada tem a ver com a verdade de um juízo particular. A principal razão que levou James a dar novas cores ao método pragmático era que ele se preocupava com a aplicação do método na determinação do significado de problemas e questões filosóficas e que, ademais, escolhera submeter a exame noções filosóficas de natureza teológica ou religiosa. Ele procurava estabelecer um critério que possibilitaria determinar se uma dada questão filosófica tinha um significado autêntico e vital, ou se, ao contrário, era trivial e puramente verbal; e, no primeiro caso, quais interesses estavam em jogo quando alguém aceitava e afirmava uma ou outra dessas duas teses em disputa. Peirce era acima de tudo um lógico; enquanto James era um educador e um humanista que desejava forçar o grande público a reconhecer que certos problemas, certos debates filosóficos, tinham importância real para a humanidade, porque as crenças que eles colocam em jogo levam a modos de conduta bastante diferentes. Se essa importante distinção não for apreendida, fica impossível entender a maioria das ambigüidades e erros pertencentes ao período posterior do movimento pragmático.

\footnotetext{
* O significado da verdade, p. 209-210. Em nota de rodapé, James fornece um exemplo dos erros cometidos em conexão com o termo "prático", citando M. Bourdeau que havia escrito que o "pragmatismo é uma reação anglo-saxônica ao intelectualismo e racionalismo da mentalidade latina... É uma filosofia sem palavras, uma filosofia de gestos e fatos, que abandona o que é geral e abraça somente o que é particular." Em sua conferência na Califórnia, James havia sustentado a idéia de que seu pragmatismo era inspirado em larga medida pelo pensamento dos filósofos britânicos, Locke, Berkeley, Hume, Mill, Bain e Shadworth Hodgson. Mas ele contrastava seu método com o transcendentalismo alemão, particularmente com o de Kant. É especialmente interessante notar essa diferença entre Peirce e James: o primeiro tentou dar uma interpretação experimental de Kant, não a priori, enquanto James tentou desenvolver o ponto de vista dos pensadores britânicos.
} 
James tomou como exemplo a controvérsia entre o teísmo e o materialismo. Se o curso do mundo for considerado como finalizado, segue-se do princípio pragmático que é igualmente legítimo afirmar que ou Deus ou a matéria é sua causa. Seja um ou o outro, os fatos são o que são, e são os fatos que determinam qual o significado a ser dado as suas causas. Conseqüentemente, o nome que podemos dar a essa causa é inteiramente arbitrário. Mas é completamente diferente se levamos o futuro em consideração. Deus tem, então, significado de poder com respeito à consolidação do triunfo final dos valores ideais e espirituais, e a matéria passa a significar um poder indiferente ao triunfo ou derrocada desses valores. E nossa vida toma uma direção diferente quando adotamos uma ou outra dessas alternativas. Nas conferências sobre o pragmatismo, publicadas em 1907, ele aplica a mesma crítica ao problema filosófico do uno e do múltiplo, o que significa dizer monismo e pluralismo, assim como a outras questões. Desse modo, ele mostra que o monismo é equivalente a um universo rígido, no qual todas as coisas estão fixas e imutavelmente unidas às outras, no qual a indeterminação, a livre escolha, a novidade e o imprevisível não têm lugar na experiência; um universo que demanda o sacrifício da diversidade concreta e complexa das coisas para alcançar a simplicidade e a nobreza de uma arquitetura estrutural. No que concerne a nossas crenças, o monismo demanda um temperamento racionalista que leva a uma atitude fixa e dogmática. O pluralismo, por outro lado, abre espaço para a contingência, a liberdade, a novidade e fornece liberdade de ação completa para o método empírico, que pode ser indefinidamente estendido. Aceita a unidade onde a encontra, mas não procura forçar a vasta diversidade dos eventos e coisas a um molde racional único.

Do ponto de vista de um educador ou de um estudante, ou se se preferir, do ponto de vista dos interessados nessa problemática, em discussões e controvérsias filosóficas, não há razão para contestar o valor dessa aplicação do método pragmático, mas não é menos importante determinar a natureza dessa aplicação. Ela proporciona meios para a descoberta de implicações, na vida humana, das concepções filosóficas freqüentemente tratadas como destituídas de importância e possuidoras de uma natureza puramente dialética. Fornece um critério para a determinação das implicações vitais das crenças que se apresentam como alternativas em qualquer teoria. Tal como James dissera, "toda a função da filosofia deveria ser encontrar as influências características que você e eu sustentaríamos em determinado momento de nossas vidas, caso uma ou outra fórmula do universo fosse verdadeira." Entretanto, ao dizer que toda a função da filosofia consiste nesse objetivo, parece que ele se refere mais ao ensino do que à construção da filosofia. Pois tal afirmação implica que as fórmulas de mundo já se encontram dadas, e que o trabalho necessário a sua produção já estivesse concluído, de modo que resta apenas definir as conseqüências que se refletem na vida a partir da aceitação da verdade de uma ou outra dessas fórmulas. 
Do ponto de vista de Peirce, o objeto da filosofia seria mais dar um significado fixo ao universo por meio de fórmulas que correspondam a nossas atitudes ou a nossos hábitos mais gerais de resposta ao ambiente; e essa generalidade depende da extensão da aplicabilidade dessas fórmulas a eventos específicos no futuro. O significado dos conceitos de "matéria" e "Deus" devem ser fixados antes que possamos até mesmo tentar alcançar um entendimento a respeito do valor de nossa crença nesses conceitos. O materialismo significaria que o mundo demanda de nós um único tipo de hábitos gerais e constantes; e Deus significaria a demanda por outro tipo de hábitos; a diferença entre o materialismo e o teísmo seria equivalente à diferença nos hábitos requeridos para enfrentar todos os fatos detalhados do universo. $\mathrm{O}$ mundo seria um na medida em que fosse possível para nós formar um único hábito de ação que levaria em consideração todas as existências futuras e que se aplicaria a elas. O mundo seria múltiplo na medida em que fosse necessário que formássemos diversos hábitos, diferentes uns dos outros e irredutíveis uns aos outros, de maneira a capacitar a apreensão dos eventos do mundo e a controlá-los. Em resumo, Peirce escrevia como um lógico e James como um humanista.

William James realizou um novo avanço no pragmatismo por meio da vontade de crer, ou como ele mesmo mais tarde a denominou, o direito de crer. A descoberta das conseqüências fundamentais de uma ou outra crença tem, indubitavelmente, uma certa influência sobre a própria crença. Se alguém almeja a novidade, o risco, a oportunidade e uma realidade estética diversificada, ele certamente rejeitará qualquer crença no monismo quando percebe claramente a implicação desse sistema. Mas se, desde o começo, ele é atraído por uma harmonia estética, por proporções clássicas, pela fixidez até o ponto mesmo de uma segurança absoluta, bem como pela coerência lógica, é bastante natural que ele tenha fé no monismo. Portanto, William James leva em consideração aqueles motivos de simpatia instintiva que desempenham um grande papel em nossa escolha de um sistema filosófico, mais do que os motivos que alimentam o raciocínio formal; e James pensava que poderíamos prestar serviço à causa da sinceridade filosófica, se reconhecêssemos abertamente os motivos que nos inspiram. Ele também sustentava a tese de que a maior parte dos problemas filosóficos, especialmente aqueles que tocam em campos religiosos, são de tal natureza que não são susceptíveis a evidências decisivas de nenhum dos lados. Conseqüentemente, James afirma o direito das pessoas escolherem suas crenças não somente em presença de provas e fatos concludentes, mas também na ausência de todas essas provas. Acima de tudo, quando a pessoa é forçada a escolher entre um significado ou outro, ou quando, pela recusa em escolher, ela tem um direito de assumir os riscos da fé, sua recusa é, em si mesma, equivalente a uma escolha. A teoria da vontade de crer levou a mal-entendidos e mesmo ao ridículo; e, portanto, é necessário entender claramente de que maneira James a 
utilizava. Sempre estamos obrigados a agir em qualquer caso; nossos atos e as conseqüências que os acompanham alteram-se realmente de acordo com as crenças que escolhemos. Além disso, pode ser que, para descobrir as provas que serão finalmente a justificação intelectual de certas crenças - por exemplo, a crença na liberdade ou a crença em Deus -, seja necessário começar a agir de acordo com tal crença.

Em suas conferências sobre o pragmatismo e no seu volume de ensaios com o título de $O$ significado da verdade, que apareceram em 1909, James estendeu o uso do método pragmático ao problema da natureza da verdade. Até aqui temos considerado o método pragmático como um instrumento na determinação do significado das palavras e da importância vital das crenças filosóficas. Nesse ínterim, temos feito alusão às conseqüências futuras que estão implicadas. James mostrou, entre outras coisas, que, em certas concepções filosóficas, a afirmação de certas crenças poderia ser justificada por meio da natureza de suas conseqüências, ou pela diferença que tais crenças fazem na existência. Mas então, por que não avançar o argumento a ponto de sustentar que 0 significado da verdade em geral é determinado por suas conseqüências? Não devemos esquecer aqui que James era um empirista antes de ser um pragmatista, e que repetidamente afirmou que o pragmatismo é simplesmente um empirismo levado às suas conclusões legítimas. De um ponto de vista geral, a atitude pragmática consiste em "olhar para além das primeiras coisas, dos princípios, das 'categorias', das necessidades supostas; consiste em olhar para as últimas coisas, para os frutos, conseqüências e fatos". Aplicar o método pragmático ao problema da verdade é apenas um passo adiante. Nas ciências naturais, há a tendência de identificar a verdade, em qualquer caso particular, com uma verificação. A verificação de uma teoria, ou de um conceito, é levada a cabo via a observação de fatos particulares. Até mesmo a teoria física mais científica e harmoniosa é simplesmente uma hipótese até que suas implicações, deduzidas pelo raciocínio matemático ou por qualquer outro tipo de inferência, sejam verificadas por meio de fatos observados. Por conseguinte, que direção deve tomar um filósofo empírico que deseja chegar a uma definição da verdade por meio de um método empírico? Ele deve, se desejar aplicar o método empírico, e sem trazer à baila a fórmula pragmática, encontrar primeiramente casos particulares a partir dos quais ele possa generalizar. Portanto, é na submissão das concepções ao controle da experiência, no processo de verificação delas, que se encontram exemplos do que se chama verdade. Portanto, qualquer filósofo que aplica esse método empírico, sem a menor inclinação favorável à doutrina pragmática, pode ser levado a concluir que a verdade "significa" verificação, ou se se preferir, que a verificação, seja ela real ou possível, é a definição de verdade.

Ao combinar essa concepção de método empírico com a teoria do pragmatismo, alcançamos outros resultados filosóficos importantes. Passamos a dar uma nova 
interpretação às teorias clássicas da verdade segundo a coerência ou a compatibilidade entre termos e a correspondência de uma idéia com uma coisa. Uma coerência simplesmente mental sem verificação experimental não nos capacita a ir além do reino das hipóteses. Se uma noção ou uma teoria têm a pretensão de corresponder à realidade ou aos fatos, essa pretensão não pode ser testada, confirmada ou refutada, exceto quando fazemos com que passe pelo reino da ação e consideramos os resultados que ela acarreta na forma dos fatos concretos observáveis. Se, ao colocar em prática a noção, chegamos aos fatos implicados ou que ela exige, então essa noção é verdadeira. Uma teoria corresponde aos fatos quando leva aos fatos que são seus conseqüentes, por intermediação da experiência. E dessa consideração, podemos generalizar pragmaticamente que todo conhecimento é prospectivo em seus resultados, exceto no caso em que as noções e as teorias, depois de terem sido primeiramente prospectivas em suas aplicações, passam por teste que as verificam. Teoricamente, entretanto, mesmo tais verificações ou verdades não poderiam ser absolutas. Elas se baseariam em certeza prática ou moral, mas sempre estão sujeitas a correções devido a conseqüências futuras não percebidas, ou em virtude de fatos observados que foram desconsiderados. Toda proposição a respeito da verdade é realmente, em última análise, provisória e hipotética, embora um grande número dessas proposições tenha sido freqüentemente verificado sem falhas, de modo que estamos justificados em seu uso como se elas fossem absolutamente verdadeiras. Mas, logicamente, a verdade absoluta é um ideal que não se pode realizar, ao menos não até que todos os fatos tenham sido registrados, ou "ensacados", como fala James, quando não será mais possível fazer outras observações e outras experiências.

Assim, o pragmatismo se apresenta como uma extensão do empirismo histórico, mas com uma diferença fundamental, não insiste sobre os fenômenos antecedentes, mas sobre os fenômenos conseqüentes; não sobre os precedentes, mas sobre as possibilidades de ação. E essa mudança de ponto de vista é quase revolucionária em suas conseqüências. Um empirismo satisfeito com a repetição de fatos passados não tem lugar para a possibilidade e para a liberdade. Não se pode encontrar lugar para concepções e idéias gerais, a não ser se as considerarmos como meros sumários ou registros. Mas quando tomamos o ponto de vista do pragmatismo, vemos que as idéias gerais têm um papel muito distinto a desempenhar, muito mais do que reportar ou registrar experiências passadas. Elas são a base para a organização das observações e das experiências futuras. Enquanto, para o empirismo, em um mundo já construído e determinado, a razão ou o pensamento geral não têm outro significado senão sumarizar casos particulares, em um mundo em que o futuro não é somente uma palavra, onde teorias, noções gerais e idéias racionais têm conseqüências para a ação, ali a razão necessariamente tem uma função construtiva. Não obstante, as concepções de razão 
têm somente um interesse secundário em comparação com a realidade dos fatos, dado que devem ser confrontadas com observações concretas.

O pragmatismo, assim, tem uma implicação metafísica. A doutrina do valor das conseqüências leva-nos a tomar em consideração o futuro. E essa consideração com respeito ao futuro nos faz considerar uma concepção de universo cuja evolução não está acabada, de um universo que ainda está, nas palavras de James, "se fazendo”, "em processo de tornar-se", de um universo até certo ponto ainda plástico.

Por conseguinte, a razão, ou o pensamento, em seu sentido mais geral, possui uma função real, criativa e construtiva, muito embora limitada. Se formarmos idéias gerais e as colocarmos em ação, produzem-se conseqüências que não seriam produzidas de outra forma. Sob essas condições, o mundo será diferente daquilo que teria sido se o pensamento não tivesse intervido. Essa consideração confirma a importância moral e humana do pensamento e sua operação reflexiva na experiência. Portanto, não é verdadeiro dizer que James tratou com desdém a razão, o pensamento e o conhecimento, ou que os considerava apenas como meios de adquirir benefícios pessoais ou mesmo sociais. Para ele, a razão tem uma função criativa, limitada porque específica, que auxilia a fazer o mundo de maneira diversa do que teria sido sem a razão. Ela faz com que o mundo seja realmente mais razoável (reasonable); ela lhe fornece um valor intrínseco. Entende-se melhor a filosofia de James quando a consideramos em sua totalidade como uma revisão do empirismo inglês, uma revisão que substitui o valor da experiência passada, daquilo que já está dado, pelo futuro, por aquilo que ainda é mera possibilidade.

Essas considerações naturalmente nos levam ao movimento chamado instrumentalismo. A apresentação que acabamos de fazer acerca da filosofia de James mostra que ele considerava as concepções e as teorias puramente como instrumentos que podem servir para a constituição de fatos futuros de uma maneira específica. Mas James devotou-se primariamente aos aspectos morais dessa teoria, ao embasamento que ela dá ao "melhorismo" e ao idealismo moral, e às conseqüências que se seguem dela no tocante ao valor sentimental e às ligações de vários sistemas filosóficos, particularmente às implicações destrutivas para o racionalismo monista e para o absolutismo em todas as suas formas. Ele nunca procurou desenvolver uma teoria completa das formas ou "estruturas" e das operações lógicas que se fundam nessa concepção. O instrumentalismo é uma tentativa de estabelecer uma teoria lógica precisa dos conceitos,

\footnotetext{
*William James disse, em uma metáfora feliz, que elas “devem ser contabilizadas" (must be cashed in) pela produção de conseqüências específicas. Essa expressão significa que elas devem ser capazes de levar a fatos concretos. Mas aqueles que não estão familiarizados com a fraseologia americana, tomam a fórmula de James como se as conseqüências de nossas concepções devessem estar estreitamente limitadas ao seu valor pecuniário. Assim o Sr. Bertrand Russell escreveu recentemente que o pragmatismo é simplesmente a manifestação do espírito comercial americano.
} 
dos juízos e das inferências em suas diversas formas, considerando primeiramente como o pensamento funciona na determinação experimental de suas conseqüências futuras. Significa dizer que o instrumentalismo tenta estabelecer distinções universalmente reconhecidas e regras de lógica, derivando-as da função reconstrutiva ou mediativa atribuída à razão. Objetiva-se constituir uma teoria das formas gerais de concepção e de raciocínio, e não deste ou daquele juízo particular ou conceito relacionado com seu próprio conteúdo, ou com suas implicações particulares.

Tão logo se leve em consideração os antecedentes históricos do instrumentalismo, dois fatores são particularmente importantes, muito mais que essa questão da verificação experimental sobre a qual já falamos em conexão com a obra de James. O primeiro desses dois fatores é psicológico, e o segundo é uma crítica da teoria do conhecimento e da lógica que resultou da teoria proposta pelo idealismo neokantiano, exposta nos escritos lógicos de filósofos tais como Lotze, Bosanquet e F. H. Bradley. Como já dissemos, a influência neokantiana era muito forte nos Estados Unidos durante a última década do século xix. Eu e as pessoas que colaboraram comigo na exposição do instrumentalismo começamos como neokantianos, da mesma forma que o ponto de partida de Peirce foi o kantismo e o de James foi o empirismo da escola britânica.

As tendências psicológicas, que têm exercido influência sobre o instrumentalismo, são mais de natureza biológica do que fisiológica. Elas estão, mais ou menos, estreitamente relacionadas com o importante movimento, cujo promotor na psicologia foi o doutor John Watson, ao qual ele deu o nome de behaviorismo. Sucintamente, o ponto de partida dessa teoria é a concepção de que o cérebro é um órgão de coordenação de estímulos sensoriais (aos quais se pode adicionar modificações causadas pelos hábitos, por memórias inconscientes, ou pelo que é hoje chamado de "reflexos condicionados"), com o propósito de efetivar respostas motoras adequadas. Com base na teoria da evolução orgânica, sustenta-se que a análise da inteligência e de suas operações deveria ser compatível com a ordem dos fatos biológicos conhecidos, concernente à posição intermediária ocupada pelo sistema nervoso central ao tornar possíveis as respostas ao ambiente, adequadas às necessidades do organismo vivo. É particularmente interessante notar que nos Studies in logical theory (Estudos de teoria lógica) (1903), que foi a primeira declaração dos instrumentalistas a respeito desse assunto, eles reconheceram o quanto deviam a William James por ter forjado os instrumentos que utilizou, enquanto, ao mesmo tempo, ao longo dos estudos, os autores declararam constantemente suas crenças numa estreita união dos princípios "normativos" da lógica com os processos reais de pensamento, na medida em que tais processos são determinados por uma psicologia objetiva ou biológica, e não por uma psicologia introspectiva dos estados da consciência. Mas é curioso notar que os "instrumentos" aos quais faziam alusão não eram as considerações de maior serventia para James. Os instrumentos 
precederam o pragmatismo jamesiano, e é em algumas páginas de seu Principles of psychology (Princípios de psicologia) que se deve procurá-los. Essa obra importante, datada de 1890 , desenvolveu realmente duas teses distintas.

Uma delas é uma reinterpretação da psicologia introspectiva, na qual James nega que as sensações, imagens e idéias sejam discretas, substituindo-as por um fluxo contínuo que ele denomina "fluxo da consciência". Essa concepção tem necessidade de considerar as relações como uma parte imediata do campo da consciência, tendo o mesmo status que as qualidades. Em toda sua Psicologia, James dá uma feição filosófica a essa concepção, utilizando-a para criticar o atomismo de Locke e o de Hume, assim como o apriorismo da síntese dos princípios racionais de Kant e de seus sucessores, dentre os quais deveria ser mencionado Thomas Hill Green, na Inglaterra, que na época estava no auge de sua influência.

O outro aspecto de seu Princípios de psicologia é de natureza biológica. Ele se mostra com toda sua força no critério que James estabelece para a descoberta da existência da mente. "A busca por fins futuros e a escolha de meios para alcançá-los são, portanto, a marca e o critério da presença de mentalidade em um fenômeno." A força desse critério fica plenamente exposta no capítulo intitulado "Atenção" e sua relação com o interesse considerado como a força que a controla, assim como sua função teleológica de seleção e integração; no capítulo intitulado "Discriminação e comparação" (análise e abstração), em que ele discute o modo pelo qual os fins são alcançados e como os meios para alcançá-los evocam e controlam a análise intelectual; e no capítulo intitulado "Concepção", onde ele mostra que uma idéia geral é um modo de significação das coisas particulares e não simplesmente uma abstração de casos particulares ou uma função supra-empírica,-que ela é um instrumento teleológico. James, então, desenvolve essa idéia no capítulo sobre o raciocínio, onde diz que "o único significado de essência é teleológico, e a classificação e a concepção são armas puramente teleológicas da mente".

Poder-se-ia completar essa breve enumeração mencionando também o capítulo do livro de James no qual o filósofo discute a "Natureza das verdades necessárias e o papel da experiência" e afirma, em oposição a Herbert Spencer, que muitos de nossos mais importantes modos de percepção e de concepção do mundo dos objetos sensíveis não são produtos cumulativos de experiências particulares, outrossim atividades biológicas originais, variações espontâneas, que se mantêm em virtude de sua aplicabilidade a experiências concretas, após terem sido criadas. Número, espaço, tempo, semelhança e outras "categorias" importantes poderiam ter sido trazidas à existência, diz ele, como uma conseqüência de alguma instabilidade cerebral particular, mas de maneira nenhuma poderiam estar registradas na mente por uma influência externa.

* Psycology, vol. I, p. 8. 
Muitos conceitos significativos e inúteis também afloram da mesma maneira. Mas as categorias fundamentais têm sido cumulativamente estendidas e reforçadas por causa de seu valor quando aplicadas a instâncias concretas e coisas da experiência. Portanto, não é a origem de um conceito, é sua aplicação que se torna o critério de seu valor; e aqui se encontra todo o pragmatismo em estágio embrionário. Uma frase de James sumariza muito bem as implicações envolvidas: "a noção popular de que a 'ciência' é imposta à mente $a b$ extra, e que nossos interesses nada têm a ver com as construções científicas, é totalmente absurda".

Dado o ponto de vista que acabamos de especificar, e o interesse em ligar uma teoria da concepção e do juízo, resulta a seguinte descrição. As adaptações feitas pelos organismos inferiores, por exemplo, suas respostas efetivas e coordenadas aos estímulos, tornam-se teleológicas no ser humano e, por conseguinte, ocasionam o pensamento. A reflexão é uma resposta indireta ao ambiente e o elemento não-diretivo pode tornarse grande e muito complicado. Mas ele tem sua origem no comportamento adaptativo biológico e a função última de seu aspecto cognitivo é um controle prospectivo das condições do ambiente. A função da inteligência, portanto, não é aquela de copiar os objetos do ambiente, mas sim de levar em consideração a maneira pela qual possam ser estabelecidas relações mais efetivas e mais proveitosas com esses objetos no futuro.

Como esse ponto de vista tem sido aplicado à teoria do juízo é uma história muito longa para ser contada aqui. Confinemos nossa discussão a dizer que, em geral, o "sujeito" de um juízo representa aquela porção do ambiente na qual a reação deve ser feita; o predicado representa a possível resposta, ou hábito, ou modo pelo qual alguém deve se comportar diante do ambiente; a cópula representa o ato orgânico e concreto pelo qual se faz a conexão entre o fato e sua significação; e, finalmente, a conclusão, ou o objeto definitivo do juízo, é simplesmente a situação inicial transformada, uma situação que implica uma mudança do sujeito original (incluindo sua mente) assim como uma mudança do próprio ambiente. A nova e harmoniosa unidade, assim alcançada, verifica a pertinência dos dados que foram inicialmente escolhidos para servir como sujeito e dos conceitos introduzidos na situação durante o processo na condição de instrumentos teleológicos para sua elaboração. Até que essa unificação final seja alcançada, os dados perceptivos e os princípios conceituais, as teorias, são simplesmente hipóteses, de um ponto de vista lógico. Ademais, a afirmação e a negação são intrinsecamente a-lógicas: elas são atos.

Uma tal investigação sumária dificilmente pretenderia ser convincente ou promissora. Entretanto, ao notar os pontos de semelhança e diferença entre essa fase do pragmatismo e a lógica do idealismo neo-hegeliano, chegamos a um ponto de suma importância. De acordo com a lógica idealista, o pensamento em última análise constitui seus objetos e mesmo o universo. É necessário afirmar a existência de uma série 
de formas de juízo, porque nossos primeiros juízos, que estão mais próximos dos sentidos, somente constituem os objetos de maneira parcial e fragmentada, e chega até mesmo a envolver um elemento de contradição em sua natureza. Daí resulta uma dialética que permite que cada tipo inferior e parcial de juízo se torne uma forma mais completa, até ao ponto em que finalmente chegamos ao juízo total, onde o pensamento que compreende o objeto inteiro ou o universo é um todo orgânico de distinções mentais interrelacionadas. É evidente que essa teoria torna magnífico o papel do pensamento, acima de qualquer proporção. É um idealismo objetivo e racional que se opõe e difere do idealismo perceptual da escola de Berkeley. O instrumentalismo, entretanto, atesta uma função positiva ao pensamento, a saber, a de reconstituir o estágio presente das coisas ao invés de simplesmente conhecê-lo. Como conseqüência, não pode haver graus intrínsecos ou uma hierarquia de formas de juízo. Cada tipo tem sua própria meta e sua validade é inteiramente determinada por sua eficácia na perseguição dessa meta. Um juízo perceptivo limitado, adaptado à situação que lhe deu ensejo, é tão verdadeiro em seu devido lugar como o juízo filosófico ou científico mais completo e significativo. A lógica, por conseguinte, leva a uma metafísica realista na medida em que aceita coisas e eventos mesmo que independentes do pensamento. Por outro lado, a lógica leva a uma metafísica idealista na medida em que alega que o pensamento faz nascer atos distintivos que modificam os fatos e eventos futuros, de tal maneira que os faz mais razoáveis, isto é, mais adequados às metas que propomos para nós mesmos. Esse elemento ideal é mais e mais acentuado pela inclusão progressiva de fatores sociais no ambiente humano acima de qualquer fator natural; de modo que as necessidades que são satisfeitas, e as metas que são alcançadas, não são mais simplesmente de caráter biológico ou particular, mas incluem também metas e atividades de outros membros da sociedade.

É natural que os pensadores continentais se interessassem pela filosofia americana na medida em que ela reflete, em certo sentido, a vida americana. Assim, deve ter ficado claro, após essa rápida exposição da história do pragmatismo, que o pensamento americano dá continuação ao pensamento europeu. Importamos da Europa nossa linguagem, nossas leis, nossas instituições, nossa moral e nossa religião, e adaptamos tais coisas às novas condições de nossa vida. O mesmo é verdade para nossas idéias. Por muitos anos, nosso pensamento filosófico foi simplesmente um eco do pensamento europeu. O movimento pragmático que delineamos no presente ensaio, assim como o neo-realismo, o behaviorismo, o idealismo absoluto de Royce, o idealismo naturalista de Santayana são todos tentativas de re-adaptação; mas não são criações de novo. Eles possuem suas raízes no pensamento britânico e europeu. Mas, dado que esses sistemas são re-adaptações, levam em consideração os traços distintivos do ambiente da vida americana. Porém, como já foi dito, não se limitam a reproduzir o que está gasto e é incompleto nesse ambiente. Não objetivam glorificar a energia e o amor à ação que as 
novas condições da vida americana exageraram. Não refletem o mercantilismo excessivo da vida americana. Sem dúvida, todos esses traços do ambiente não podem deixar de ter certa influência no pensamento filosófico americano; nossa filosofia não seria nacional ou espontânea se não estivesse sujeita a essa influência. Mas a idéia fundamental que os movimentos sobre os quais discorremos procuram expressar é a idéia de que a ação e a oportunidade justificam a si mesmas somente até o grau em que fazem com que a vida seja mais razoável e aumentem seu valor. O instrumentalismo sustenta que, em oposição a muitas tendências contrárias dentro do ambiente americano, a ação deveria ser inteligente e reflexiva, e que o pensamento deveria ocupar uma posição central na vida. Essa é a razão de nossa insistência sobre a fase teleológica do pensamento e do conhecimento. Se tiver que ser teleológico em particular e não simplesmente em abstrato, isso provavelmente se deve ao elemento prático que se encontra em todas as fases da vida americana. Embora possa ser assim, o que insistimos acima de tudo é que a inteligência é considerada como a única fonte e garantia de um futuro feliz e desejável. Não há dúvida de que o caráter progressivo e instável da vida americana e da civilização facilitou o nascimento de uma filosofia que considera o mundo como algo em formação contínua, onde ainda há espaço para o indeterminismo, para o novo e para um futuro real. Mas essa idéia não é exclusivamente americana, embora as condições da vida americana tenham ajudado tal idéia a tornar-se autoconsciente. Também é verdade que os americanos tendem a subestimar o valor da tradição e da racionalidade quando consideradas como uma realização do passado. Mas o mundo também deu provas de irracionalidade no passado e essa irracionalidade está incorporada em nossas crenças e em nossas instituições. Há tradições ruins assim como há boas: é sempre importante fazer a distinção. Nossa negação das tradições do passado, incluindo o que quer que isso implique a respeito do empobrecimento de nossa vida espiritual, tem sua compensação na idéia de que o mundo está recomeçando e se transformando sob nossos olhos. O futuro assim como o passado podem ser fontes de interesse e consolação, e dão sentido ao presente. O pragmatismo e o experimentalismo instrumental colocam em proeminência a importância do indivíduo. É ele quem é detentor do pensamento criativo, o autor da ação e de sua aplicação. O subjetivismo é uma velha história na filosofia; uma história que começou na Europa e não na América. Mas a filosofia americana, nos sistemas que expusemos, fornece ao sujeito, à mente individual, uma função prática mais do que epistemológica. A mente individual é importante porque somente ela é o órgão de modificações nas tradições e instituições, o veículo da criação experimental. O individualismo parcial e egoísta da vida americana deixa suas marcas em nossas práticas. Para o melhor e para o pior, dependendo do ponto de vista, transformou o individualismo estético e fixo da velha cultura européia em um individualismo ativo. Mas a idéia de uma sociedade de indivíduos não é estranha ao 
pensamento americano; ela penetra até mesmo em nosso individualismo presente que é irrefletido e brutal. E o indivíduo que o pensamento americano idealiza não é o indivíduo per se, um indivíduo fixo, em isolamento e estabelecido por si mesmo, mas um indivíduo que evolui e desenvolve-se em um ambiente natural e humano, um indivíduo que pode ser educado.

Se me pedissem para fornecer um paralelo histórico a esse movimento do pensamento americano, recordaria o leitor da filosofia francesa do iluminismo. Todos sabem que os pensadores que fizeram aquele ilustre movimento foram inspirados por Bacon, Locke e Newton; o que os interessava eram as aplicações do método científico e as conclusões de uma teoria experimental do conhecimento para os assuntos humanos, a crítica e a reconstrução das crenças e das instituições. Como Höffding escreve, eles foram animados "por uma efervescente fé na inteligência, no progresso e na humanidade”. E, certamente, não são acusados, hoje em dia, justamente por causa de sua significância educacional e social, de terem tentado subordinar a inteligência e a ciência a objetivos utilitários ordinários. Procuraram simplesmente livrar a inteligência de suas impurezas, dando-lhe soberania. Não se pode dizer que aqueles que glorificaram a inteligência e a razão em abstrato, por causa de seu valor para os que encontram satisfação em sua posse, estimam a inteligência mais verdadeiramente do que aqueles que desejam fazer dela um guia indispensável da vida intelectual e social. Quando um crítico americano diz que o instrumentalismo considera as idéias simplesmente como servas que proporcionam sucesso na vida, ele somente reage, irrefletidamente, a associações verbais ordinárias com a palavra "instrumental", assim como muitos outros reagem da mesma maneira com respeito ao uso da palavra "prática". De maneira semelhante, um autor italiano recente, depois de dizer que o pragmatismo e o instrumentalismo são produtos característicos do pensamento americano, acrescenta que esses sistemas "consideram a inteligência como um mero sistema de crenças e, conseqüentemente, tentam restabelecer a dignidade da razão fazendo-a uma máquina para a produção de crenças úteis à moral e à sociedade". Tal crítica não se sustenta. De modo algum esses sistemas perseguem a produção de crenças úteis à moral e à sociedade. Mas a formação de uma fé na inteligência, como a única e indispensável crença necessária à moral e à vida social. Quanto mais se aprecia o valor intrínseco, imediato e estético do pensamento e da ciência, quanto mais se toma consciência de que a própria inteligência acrescenta alegria e dignidade à vida, tanto mais se sente pesar frente à situação em que o exercício e a alegria da razão encontram-se limitados a um grupo social restrito, fechado e técnico, e tanto mais dever-se-ia perguntar como seria possível fazer todos os homens participantes desse inestimável bem. 
Notas a $O$ desenvolvimento do pragmatismo americano

\section{Notas}

1 Esta tradução foi feita a partir de Dewey, 1981 [1931]. Entretanto, o texto tem uma história interessante. Foi publicado originalmente em francês em 1922 e em uma primeira versão inglesa, traduzida do francês, em 1925. Passou depois a fazer parte do livro Filosofia e civilização (Philosophy and civilization), publicado em 1931.

2 Dewey está se referindo a Benjamin Peirce, professor em Harvard e figura de destaque na direção da Geodetic and Coast Survey, a primeira agência de pesquisas norte-americana. 